\title{
Effect of Particle Size and Concentration on Mechanical and Electrical Properties of the Mica Filled PVC
}

\author{
S.P. Deshmukh ${ }^{1}$, A.C. Rao ${ }^{1}$, V. R. Gaval ${ }^{1}$, Seena Joseph ${ }^{2}$, P.A. Mahanwar ${ }^{2} *$ \\ ${ }^{1}$ Department of General Engineering, Institute of Chemical Technology, \\ Matunga, Mumbai-400019, India. \\ ${ }^{2}$ Department of Polymer engineering and and Surface Coating \\ Institute of Chemical Technology, Matunga, Mumbai-400019, India. \\ * Corresponding Author: pmahanwar@yahoo.com
}

\begin{abstract}
The performance of the composites is determined on the basis of the interface bonding of the filler and the polymer matrix. Particulate filled polymer composites are used extensively for their wide range of applications at low cost. In this study, the effect of the mica with different particle size and different filler concentration (10 to 50 weight percent) on the mechanical and electrical properties of the polyvinyl chloride $(P V C)$ was investigated. The PVC composites of water ground mica were prepared by Haake Rheocord 9000 machine, with Rheomix 600 using rotor type roller blades. Mechanical properties such as stiffness, and Young's modulus of the PVC mica composites were found increasing with increase in mica loading, whereas elongation at break and tensile strength was found to be decreasing with the mica loading. Dielectric strength and surface resistance were found increasing with increasing mica loading whereas there was no significant increase of arc resistance of the composites. Morphological studies revealed that there is good dispersion and wetting of the mica with PVC matrix. SEM micrographs of the composites were studied for finding the filler dispersion and fracture analysis of the test samples.
\end{abstract}

Keywords: PVC composite, mica, Scanning Electron Microscope (SEM), Water Ground Mica (WGM) 


\section{INTRODUCTION}

PVC is the most used polymer for variety of general purpose domestic, industrial applications and for wiring and cable insulation and sheathing, taking about $70 \%$ of the compounded polymers used by the industry and it is likely to retain its importance among thermoplastic compounds. It is much more readily miscible and compatible than other polymers with large number of molecular weight compounds to give wide differing mechanical properties from rigid to flexible. Compounded PVC, more than any other plastic material, is considered most versatile plastic. It can be formulated to be non-toxic, nonflammable, light, and stable and stain resistance through proper formulations. Mica has been extensively used as reinforcing filler for thermosets and thermoplastics because of its influence on the physical, mechanical and electrical properties of composites. Mica has the modulus of $172 \mathrm{GN} / \mathrm{m}^{2}$ against $73 \mathrm{GN} / \mathrm{m}^{2}$ of the glass flakes; hence its choice as filler for reinforced composite is obvious. Mica has excellent chemical and corrosion resistance, good electric properties, low thermal expansion and cause less wear and abrasion to the processing equipment ${ }^{[1]}$.

Maine et al. ${ }^{[2]}$ has suggested that the most promising area of full utilization of the planner reinforcing properties of mica is in sheet materials, although other fabrication techniques can be used. Processing, applications, and properties of mica filled composites have been reviewed in many references. The notable nature of mica leads to the initial breakage and delamination of the mica particles during processing, such that the initial dimensions of the mica changes significantly influencing the properties of the composites.

There is extensive literature explaining changes in the mechanical properties of the mica filled composites. In all the studies it has been clearly demonstrated that the modulus and the stiffness are the easiest mechanical properties to estimate, since these properties largely depends on particle size, modulus, geometry, distribution and filler loading ${ }^{[3]}$. The tensile strength of the filled polymer is difficult to predict as it depends on the interfacial bonding of the filler and polymer in addition to the above.

A number of investigations has shown that modulus and the stiffness of the mica filled composites increase with the filler concentration irrespective of the particle size of the mineral filler. The tensile strength of the composite totally depends on the strong adhesion of filler and polymer and the wetting ability of the polymer. For good wetting low surface tension, low viscosity of the polymer matrix and similar polarities of both the phases are essential ${ }^{[4]}$. Normally thermosetting polymers are low viscous liquids and are converted to solids by crosslinking and many of thermosetting polymers are polar in nature.

Mica addition to polymers also shows significant changes in dielectric properties of the plastics

${ }^{[5]}$. These changes in the electrical properties of the mica filled polymer composites make them 
suitable for their use in electrical insulation applications on large extent ${ }^{[6]}$. The study carried out on the mica filled PVC composites of varying size and different filler concentration reveals changes of the mechanical and electrical properties of the composites

\section{EXPERIMENTAL}

\subsection{Materials}

PVC mica composites of different formulations were prepared for research work to develop the final compression molded sheets. PVC resin of $\mathrm{k} 67$ grade, manufactured by Reliance Industries Ltd., India was used for this work. INSTABEX C-11, one pack stabilizer ( $66-72 \% \mathrm{~Pb}, 71.1-$ 77.55\% $\mathrm{PbO}, 3.2-3.8 \mathrm{Sp}$. gr. and $1 \%$ maximum moisture) supplied by $\mathrm{m} / \mathrm{s}$ Aryavart Chemicals Pvt. Ltd India was used as the stabilizer for the experimental work. Stearic acid was used as lubricant and was supplied by $\mathrm{m} / \mathrm{s}$ Godrej Industries Ltd. Dioctyl phthalate (DOP) was used as a plasticizer for compounding. Water ground high aspect ratio (20 - 40) lustrous filler mica of WGM 101, WGM 202, and WGM SIL supplied by M/s Galaxy Corporation, Mumbai, India was used in different proportions of $10 \mathrm{phr}$ to $50 \mathrm{phr}$ in the range of $10 \mathrm{phr}$ in every stage. The particle size and surface area of different types of mica used in this study are given in Table 1. Virgin test samples were prepared with the PVC with all the additives such as stabilizer, lubricant and plasticizer but without filler.

\subsection{Preparation of the Test Specimens}

\subsubsection{Dry blending}

For different composite formulations weight of resin, stabilizer, lubricant and plasticizer were kept uniform and mica was added in different weight proportions. The aim of this research study was to determine use of mica as filler in PVC to develop composite with improved mechanical and electrical properties. The weight proportions of the resin, lubricant, stabilizer and plasticizer were selected based on the PVC cable formulations reported and the formulation is given in Table 2. Water ground mica of different particle sizes and different surface area was used in these formulations.

Table 1. Size of water ground mica used for formulations.

\begin{tabular}{|c|c|c|}
\hline Wet Ground Mica Type & Particle size (microns) & Surface area $\left(\mathrm{m}^{2} / \mathrm{gm}.\right)$ \\
\hline WGM 202 & 74 & 2 \\
\hline WGM SIL & 44 & 4.8 \\
\hline WGM 101 & 150 & 1.4 \\
\hline
\end{tabular}


Table 2. PVC formulation for study.

\begin{tabular}{|c|c|}
\hline PVC Resin & $100 \mathrm{gm}$ \\
\hline Liquid DOP & $50 \mathrm{gm}$ \\
\hline INSTABEX C-11 & $4 \mathrm{gm}$ \\
\hline Stearic Acid & $1 \mathrm{gm}$ \\
\hline Mica & 10 to $50 \mathrm{gm}$ \\
\hline
\end{tabular}

PVC resin, INSTABEX C-11, mica, and stearic acid were dry blended using high-speed mixer for five minutes. Liquid DOP was added in two to three stages during dry blending. The dry blending process was carried out at $105^{\circ} \mathrm{C}$.

\subsubsection{Melt compounding}

Dry blended mixtures of different formulations were melt compounded using Haake Rheocord 9000 batch compounding machine. Roller blades Rheomix 600 were used for compounding of the mix. Dry blended PVC mix of 60-gram weight was added to the machine to compound it in different batches. Ten batches of each such compound were processed as per the processing parameters given in Table 3. During compounding it was observed that the, processed PVC mix was non sticky and was able to remove from blades easily. The compounded mix was then allowed to cool to room temperature before it was packed in labeled plastic packets.

Table 3. Process parameters for Haake Rheomix 600.

\begin{tabular}{|c|c|c|}
\hline Processing Temperature & Roller Speed (r.p.m) & Processing time (Minutes) \\
\hline $180^{\circ} \mathrm{C}$ & 60 & 5 \\
\hline
\end{tabular}

\subsubsection{Compression molding}

The compounded PVC composite was dried in oil heated electric oven at $105^{\circ} \mathrm{C}$ for the period of one hour to remove the moisture present in the material before it was compression molded in test sheets at $180^{\circ} \mathrm{C}$ temperature and $130 \mathrm{~kg} / \mathrm{cm}^{2}$ mold pressure. The compression-molded sheets of 90 gm weight and $180 x 180 \mathrm{~mm}$ size with $2 \mathrm{~mm}$ thickness were made. The hydraulic compressionmolding machine was used for the study. The die was cooled to $40^{\circ} \mathrm{C}$ at the process pressure of $130 \mathrm{~kg} / \mathrm{cm}^{2}$. These sheets were then used for determining mechanical and electrical properties of the PVC composites. 


\subsubsection{Mechanical properties}

Mechanical properties of the test specimen were evaluated as per ASTM D 638 using Universal Testing Machine LR 50K from Lloyd Instruments Ltd., U.K. at cross head speed of 50mm/min. Five samples of each composite were tested for finding average values of mechanical properties.

\subsubsection{Electrical properties}

The dielectric strength was investigated as per ASTM D 149 using Zaran Instruments (India) with $2 \mathrm{~mm}$ thick test samples of the composites. The voltage for this test was slowly increased to penetrate the sample and its maximum values were noted. The instrument was having input configuration of $240 \mathrm{~V}, 50 \mathrm{~Hz}, 1 \mathrm{PH}$ with $0-50 \mathrm{~K} \mathrm{~V}$ output at $100 \mathrm{~mA}$ with 15 minutes rating.

The arc resistance of test specimen was carried out as per ASTM D 495-89, which is high voltage, low current test. Arc resistance was determined using Zaran Instrument with $2 \mathrm{~mm}$ thick composite sheets.

The surface resistance tests were carried out as per ASTM D 257 using HP 4339 B high resistance meter of Hewlett Packard, surface testing machine. The Electrode diameter machine was $2.5 \mathrm{~cm}$ with output voltage of $500 \mathrm{~V}$ and the current limit of $500 \mu \mathrm{A}$.

\subsubsection{Morphological properties}

SEM was used to study morphology of the mica PVC composites. SEM studies of tensile test fractured and liquid nitrogen fractured samples were carried out using JSM-6380LA Analytical Scanning microscope of Joel make, Japan. The Samples were sputter coated with platinum to increase the surface conductivity using JFC-1600 auto fine coater of Joel Make Japan.. The digitized images of the samples were recorded and studied.

\section{RESULTS AND DISCUSSION}

\subsection{Stiffness and Young's Modulus}

The effects of concentration of mica and its size on the mechanical properties of the PVC composites are presented in Figures 1 and 2. From the results it is found that stiffness and Young's modulus of the composite was increasing with increase of the filler content. It was observed that the increase in stiffness as well as Young's modulus of the composite is attributed to the platy structure of the mica. The rate of increment of stiffness as well as Young's modulus varies with varying particle size of mica. The stiffness and the Young's modulus variation and its 
percent increment with increase in concentration clearly indicate the dependence of particle size and its dispersion. Shepherd et al ${ }^{[7]}$ have found that the use of mica increase stiffness, Young's modulus and dimensional stability of some common polymers. Addition of mica in polymer influences filler matrix which is responsible for variation in mechanical properties of composites. It is observed that at 30 weight percent filler loading of each type of mica showed stiffness increase above $300 \%$, indicating maximum level of dispersion whereas the Young's modulus is higher at 50 weight \% loading of WGM SIL mica having $44 \mu \mathrm{m}$ size. At this loading the Young's modulus is same for WGM 101 mica and WGM 202 mica indicating optimum level of dispersed platelets. It clearly indicates that stiffness and Young's modulus depends on extent of dispersion as well as dispersion of agglomerates.

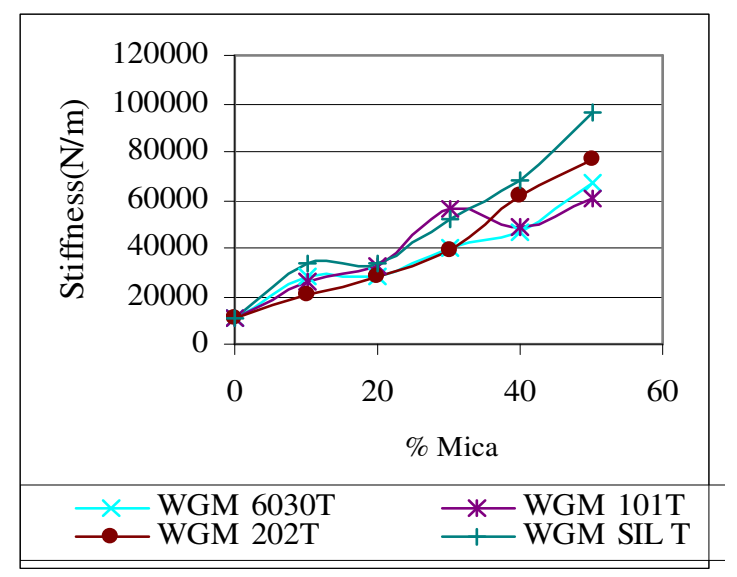

Figure1. Stiffness of mica filled PVC composites.

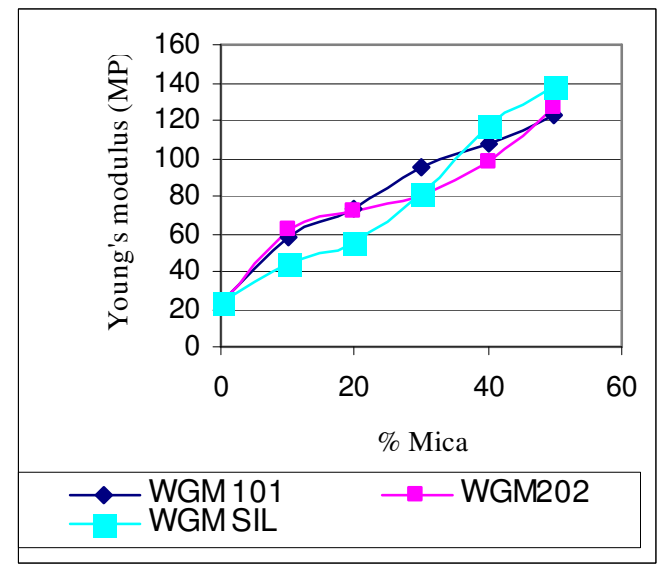

Figure 2. Young's modulus for mica filled PVC composite.

It is also indicated that the agglomerates at 30 and 50 weight $\%$ also support the extent of dispersion and property variation. Figures 3, 4, and 5 show SEM of the liquid $\mathrm{N}_{2}$ fractured surfaces of $10 \%, 30 \%$ and $50 \%$ mica filled PVC composites. It is observed from the SEM 
photographs that, at 30 weight $\%$ mica, the agglomeration is started due to which poor dispersion of mica in polymer matrix has been observed, whereas at 50 weight $\%$ mica agglomerates are observed but these agglomerates are in dispersed form as compared to 30 weight \% mica PVC composite. Thus the trend in increment in stiffness and Young's modulus is clearly dependent on the extent of dispersion of the particles of mica in polymer. As the maximum increase in the Young's modulus of test composite is found to be over 300 percent, it suggests that there was proper bonding between filler and matrix.

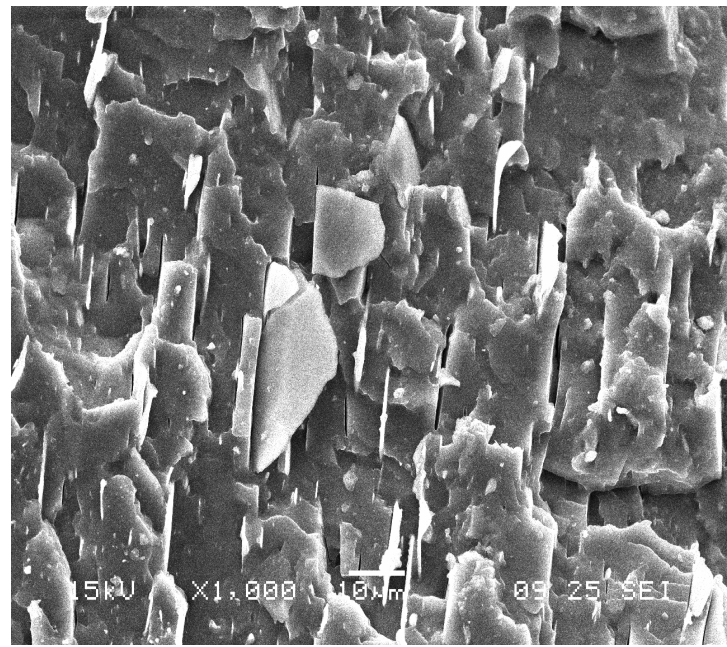

Figure 3. SEM: Liquid nitrogen fractured, $10 \mathrm{phr}$ WGM SIL mica filled PVC composite.

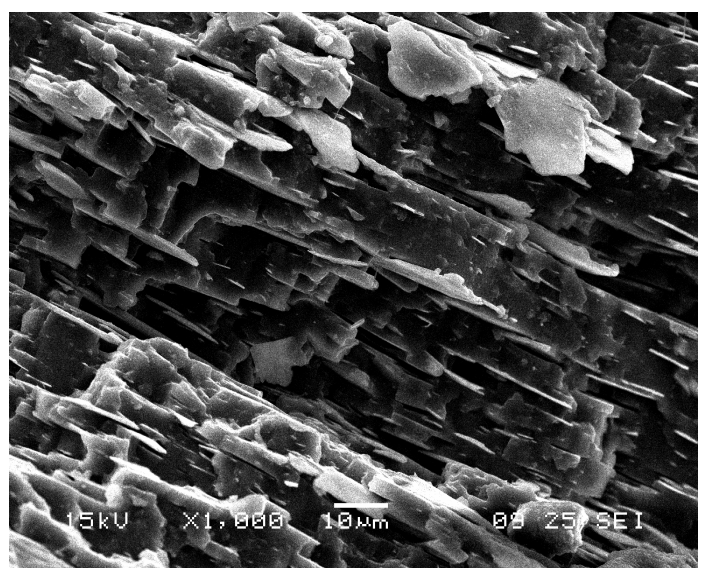

Figure 4. SEM Liquid nitrogen fractured, $30 \mathrm{phr}$ WGM SIL mica filled PVC Composite. 


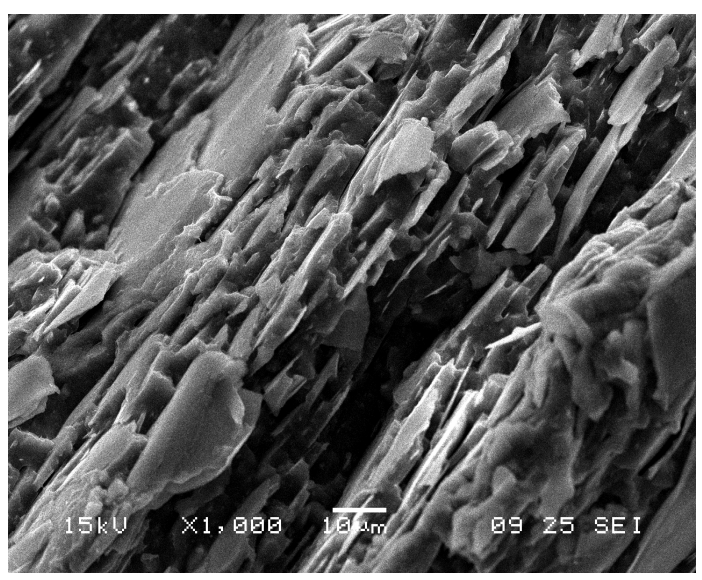

Figure 5. SEM: Liquid nitrogen fractured, 50 phr WGM SIL Mica filled PVC Composite.

\subsection{Tensile Strength and Extension at Break}

The elongation at break and tensile strength values of mica filled PVC composites at different filler content are given in Figures 6 and 7. It is observed that the tensile strength and elongation at break decrease with increasing concentration of filler loading of each type of PVC composite. The decrease in tensile strength as well as elongation attributes to restriction of polymer chain movements. It is also supported by variation in rate of change of tensile strength with increase in concentration of filler. The rate of decrease in tensile strength is higher at higher filler loading. This rate of decrease in tensile strength is higher for higher particle size as compared to smaller particle size of mica. Raj et al. ${ }^{[8]}$ in their studies have found that elongation and tensile strength of composite decreases with increase in particulate filler concentration. The extent of dispersion also plays an important role in varying the properties of mica filled composite. Even though, there was proper filler and matrix bonding, this bonding appeared unable to withstand shear strain and elongations at rupture of mica filled composites failing it catastrophically. 


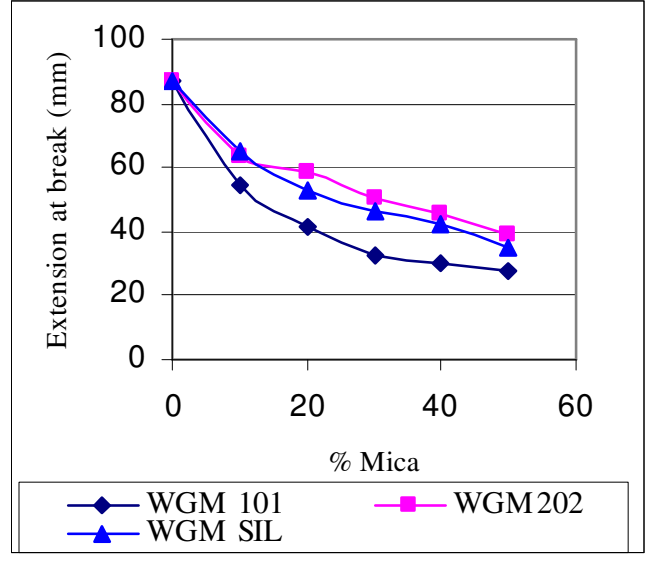

Figure 6. Extension at break for mica filled PVC composite.

From the trend in variation in mechanical properties of the PVC composite, it is clear that, as the concentration of filler increases the polymerr chain moment and displacement due to applied force is reduced. It has been shown Figure 7 that in the fiber reinforced matrix there will be a distribution of tensile and compressive micro stresses present in the matrix with tensile stresses more likely at low volume fractions, and it is possible that these stresses may generate interface cracking. In the flakes, the possibility of a tensile stress near the periphery of the flakes is low. However, between two neighboring flakes and away from the edges, a tensile stress is likely to develop to maintain overall equilibrium. As indicated by Gupta et al. ${ }^{[9]}$ strength reduction in mica filled PVC composite in relation with virgin (neat) PVC could be attributed to formation of micro cracks in the resin matrix due to the internal stresses developed during curing and difference in the thermal shrinkage of PVC and mica.

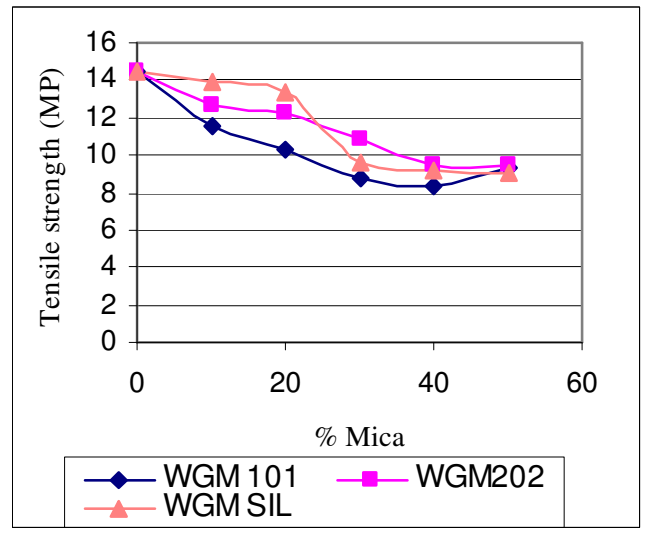

Figure 7. Tensile strength for mica filled PVC composites. 
It is most likely that the addition of the mica influence fiber/matrix adhesion, which is responsible for the mechanical property variation with mica content ${ }^{[7]}$. The interfacial shear strength is one of the most important parameter controlling strength and toughness of composites.

The lowering of the extension of the mica filled PVC composite may be associated with weak fiber/matrix adhesion. The weak filler polymer matrix has less elongation at break as compared neat polymer. More filler content of the polymer matrix reduces its elongation considerably.

\subsection{Electrical Properties}

The dielectric strength, surface resistance and arc resistance for test specimens with increasing mica content in PVC are shown in Figures 8, 9 and 10. Small mica addition in PVC acts as a intermolecular plasticizer and is able to penetrate the molecules of the PVC, leading to chain separation. This leads to the increase in the some of the dielectric properties of the materials. At higher loading of mica, it acts as an intramolecular plasticizer, where the mica molecules distributed in inter aggregate space. This hinders the polymer chain elongation and consequently reduces some dielectric properties ${ }^{[7]}$.

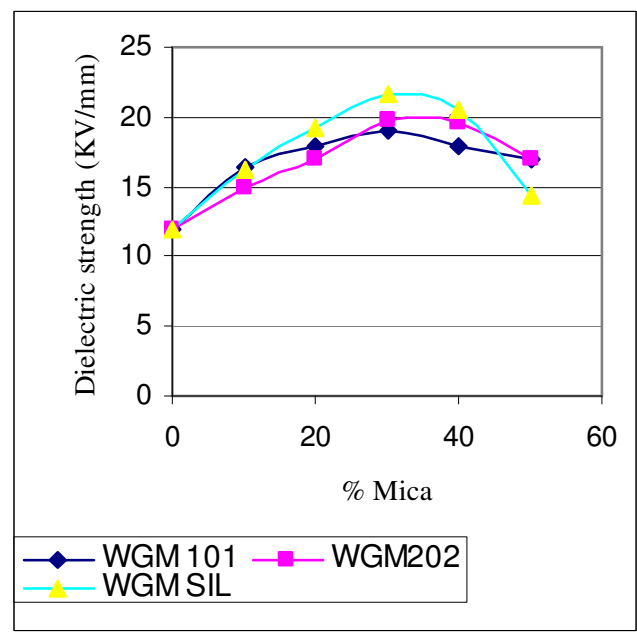

Figure 8. Dielectric strength for mica filled PVC composite. 


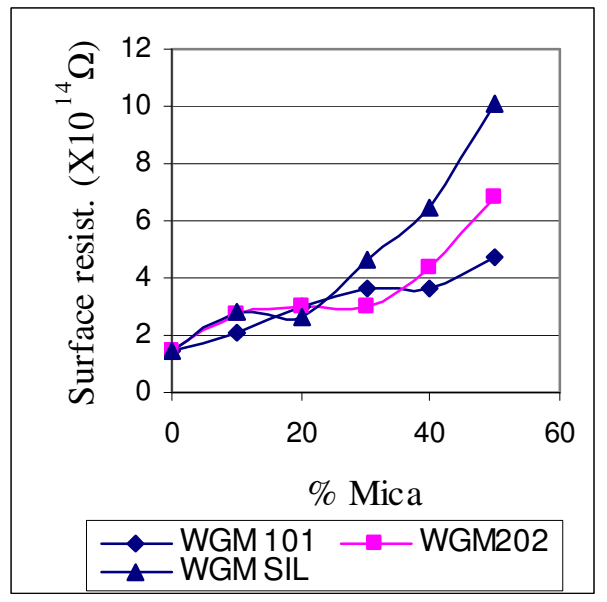

Figure 9. Surface resistance for mica filled PVC composites.

From the Figure 8, it has been shown clearly that the dielectric strength of the mica filled PVC composite has been increasing with mica content up to 30 weight percent, as mica has good electric resistance and it slightly reduces after it. For WGM SIL mica of $44 \mu \mathrm{m}$ particle size, the percent increase was as high as $180.8 \%$. For other mica fillers the dielectric strength has been found increased considerably. This may be explained as follows. As the SEM micrographs (Figures 3, 4, and 5) shows, the resin is more densely packed in the sample containing 30 and 40 parts by weight of mica filler, while in the samples of low loading of mica, the resin is relatively loosely packed. Since dense packing will hinder displacement of the dipoles and also hinder the accumulation of charges at the filler resin interphase, and since dielectric strength is directly related to these two factors the rate of increase is observed ${ }^{[7]}$.

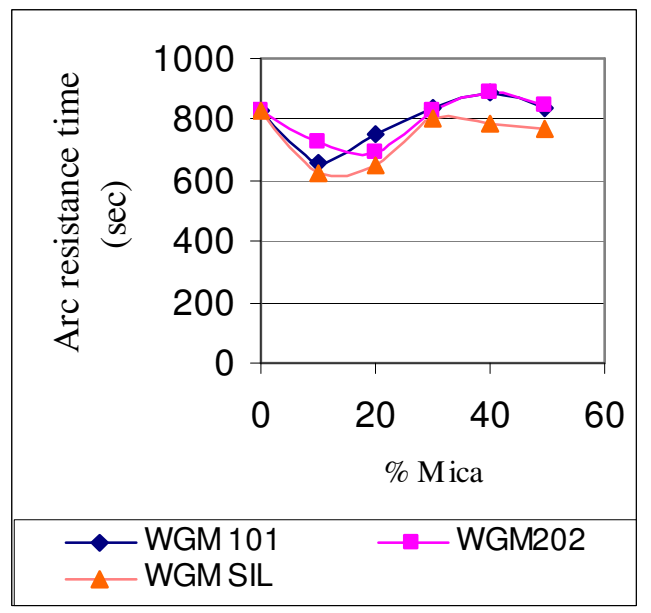

Figure 10. Arc resistance for mica filled PVC composite. 
Presence of chlorine atoms in the polyvinyl chloride molecules determines an increased polarity in comparison with other polymers such as polyolefin. Electrical resistivity is the most important representative characteristic for cable insulation. It depicts the structural integrity under the action of the electrical field, and electron availability as charge carrier. For PVC the energy transfer from it is consumed for bond scission which is followed by the remote of hydrochloric acid, and the increase in the unsaturation level, or by cross linking. Consequently the electrical resistance will take certain values according to the modifications of the composition of the insulating material.

Arc resistance of the composite also shows variation for the 10 and 40 and 50 parts by weight (Figure 9). For the 10gm weight for the WGM SIL mica filled PVC composite the reduction in the arc resistance was 24 percent. It has been observed in Figure 10, that there is variation in surface resistance of the composite. For the WGM SIL mica of $44 \mu \mathrm{m}$ the increase in surface resistance is 3 times more surface resistance of neat PVC matrix and also more as compared to mica PVC composites with bigger mica particle size i.e. WMG 101 and WGM 202.

\subsection{Fracture Morphology}

Liquid nitrogen fractured and tensile test fractured surfaces of the mica filled PVC composites are shown in Figures 3, 4, 5, 11 and 12. The possible origins of the crack in these composites are voids or air bubbles, resin rich areas, particle size of the fillers and poor mica and matrix adhesion. Figures 3, 4 and 5 show brittle fractures of the composites. For the tensile tested composite specimens the debonding at the interface of the mica and PVC matrix shows pullout of the mica particles showing voids of bigger size. This mainly happens due to lack of proper interfacial adhesion.

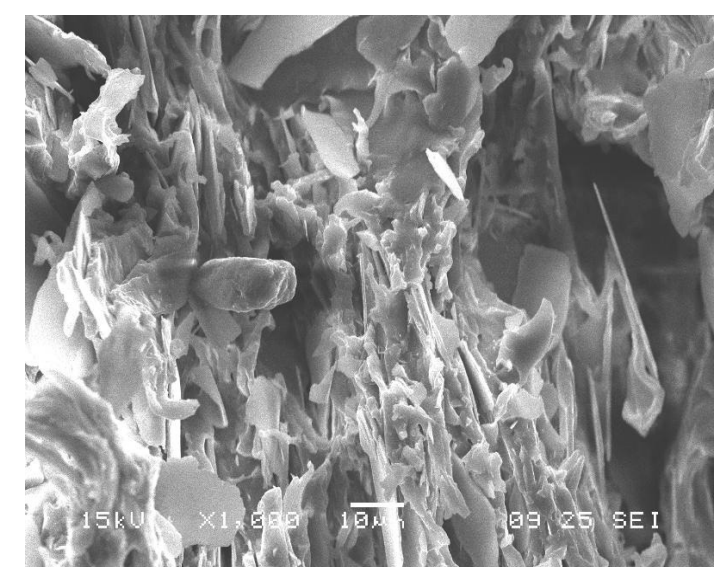

Figure 11. SEM of tensile fractured surface, $30 \mathrm{phr}$ WGM SIL mica filled PVC composite. 


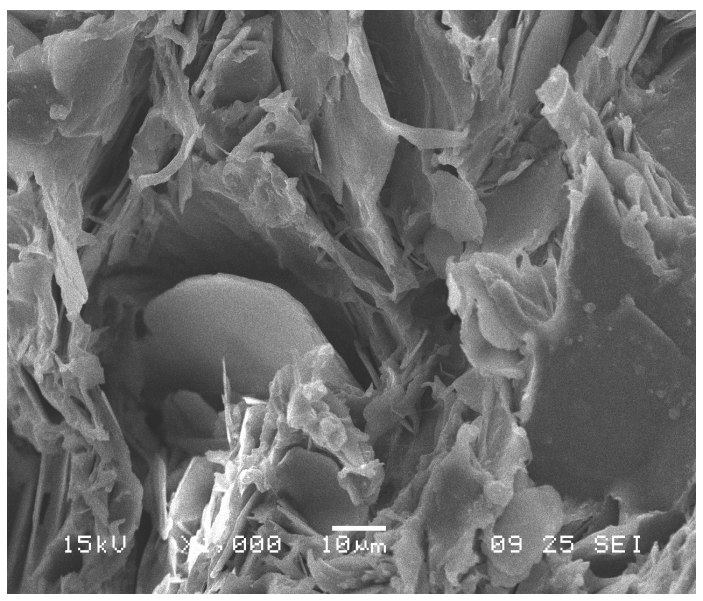

Figure12. SEM of tensile fractured surface with 50phr WGM SIL mica filled PVC composite.

The micrographs clearly shows that the mica particles are randomly oriented and large number of particles are subjected to tensile stresses acting on the planes perpendicular to them where crack propagation takes place. As the mica is having low splitting energy it undergoes delamination. High levels of particle pull out; occur due to low strength values and low elongation at break.

\section{CONCLUSION}

From the study of the mica filled PVC composites prepared from mica of different particle size and with different filler concentration following results can be concluded:

Stiffness and Young's modulus of the mica filled composite have been found increasing with the higher percent of mica content in the composite. For composites of mica with small particle size the rate of increase was slightly more as compared mica with higher particle size. This has been mainly observed because the filler was properly dispersed in the matrix and there was good bonding of filler and PVC matrix.

Extension at break and tensile strength of the composite was found reducing with increase in filler concentration. This is due to the fact that the strength of filler is higher than the strength of PVC matrix which leads to decrease in adhesion between filler and matrix.

Dielectric strength of the mica filled PVC composite was found increasing up to 30 percentage filler concentration and then reduced marginally for further increase in filler concentration. Surface resistance was found increasing with increase in filler concentrations for mica of all particle sizes where as there was no significant change in the arc resistance of the composite irrespective of filler concentration and particle size of the mica. 


\section{REFERENCES}

1. P. Bajaj, NK Jha, Anand Kumar, J Appl. Polym. Sci. Vol 44, 1921-1930 (1992)

2. F. Maine, P. Sheperd, Composites 5, (1993), 1974

3. Fenton,Malcom, Hawley, George, Pol. Composites, vol. V3, Issue N4, pg. 218-229, Oct.82

4. R. Zhao., J. Huan., B. Sun., G. Dai., J. Appl. Polym. Sci.. vol. 82, 2719 - 2728 (2001)

5. M. A. Osman, A Atallah, M. Muller. U. W. Suter., Polymer, 42 (2001)6545-6556

6. A. Tripathi, A. K. Tripathi, P.K.C. Pillai, J of Mtl Sci. Letters, 9, pg. 443-45, (1990).

7. P. D. Shepherd, F.J. Golembwa, F.W. Maine., Fillers and Reinforcement for Plastics.

8. RG Raj, BV Kokta, C Daneault, J Appl. Polym. Sci. Vol 40, 645-55 (1990)

9. V. B. Gupta., C. Brahatheeswaran., J. Appl. Polym. Sci.. vol 52, 107- 118 (1994)

10. P. Bataille, T. Bui., Polymer Composites, vil. 2, issue 1, 8-12 (2004)

11. C. Richard, K. Hing, H.P. Schreiber, Polymer Composites, vol. 6, issue 4, 201-208 (2004) 